\title{
Working with teachers to enable both student and teacher learning
}

\author{
Margaret Walshaw
}

Published online: 8 February 2011

(C) Springer Science+Business Media B.V. 2011

Over recent years, concerns about mathematics underachievement and, by implication, mathematics teaching have loomed larger than ever in educational discourses across the world. For example, in New Zealand, the discourse of 'mathematical underachievement' has been most keenly expressed within political, business and media fora and has resulted in the passing of a new national policy on National Standards. There are important synergies between the educational climate New Zealand currently experiences and those in many other nations, where educational policy is constructed around so-called crises that are used to fuel and sustain wider agendas. In these kinds of environments, nations have typically responded with a back to basics appeal that privileges certain fundamentalist interests, values and practices.

How does this new educational climate animate thinking about teaching? Contemporary thinking about teaching is based around the idea that teachers are responsible for students' lack of proficiency, even as teaching is constructed as a 'political panacea'. Given this understanding, teachers and teaching have become objects of scrutiny and critique and, as a result, on a day-to-day basis in many classrooms, the content of what is present in pedagogical experience has changed. Demands for increased testing and attempts to script teaching operate within a context in which teachers confront heavy workloads, new technologies and new curricular mandates, all of which operate to regulate their teaching practice and to shape their embracement of specific behaviours that render them deferential and compliant. In some contexts, there are high stakes and consequences involved for teachers who refuse to submit to such systems.

What is enormously uplifting is the realisation that within the new audit culture of our educational systems, there do exist identifiable spaces for manoeuvre. This is apparent within the four articles in this issue of the Journal of Mathematics Teacher Education. Each article carves out its own borders far beyond the discourse of pedagogical deficiency and ineffectiveness, providing us with ways to imagine a space for creative change. Each assists us in thinking about constructing teaching practices that are responsive and appropriate to specific sites. Each allows us to consider a pedagogical practice that is more

M. Walshaw $(\bowtie)$

Massey University, Palmerston North, New Zealand

e-mail: m.a.walshaw@massey.ac.nz 
desirable than one that equates pedagogical competency with heightened standardised performance measures. Importantly, as teachers, educators and researchers, the articles give us pause for reflecting on how the education of mathematics teachers might be improved and how teaching approaches might be developed to enable students' successful learning of mathematics.

Every aspect of teaching, from task and activity, organisation and environment, routines and rituals, to assessment and critique, interaction and discourse, is framed by values, priorities and purpose. In "Zen and the art of neriage: Facilitating consensus building in mathematics inquiry lessons through lesson study," the author Noriyuki Inoue describes an aspect of teaching that is culturally specific to Japan. Neriage is centred on whole-class discussions in which the teacher compares and contrasts different students' strategies and, rather than pointing to the best solution, works to build consensus amongst students. Inoue was interested in exploring whether the culturally specific Japanese approach might be implemented effectively in US classroom settings. A series of video-based lesson studies was employed as a model for professional development with a group of six 4th and 5th grade teachers. In this intervention, the key objective of the study was to enhance teachers' effectiveness in building student consensus within students' discussions.

The teachers in the study, like many teachers, found it difficult to hold back their own explanations until deemed crucial. However, they learned that students require an opportunity to look at the pros and cons of a particular solution. The teachers learned to make provision for students' involvement in taking and defending a particular position against the claims of other students. They learned to scaffold students' attempts at examining premises, disagreements and counter arguments. They learned to elicit negotiation and social construction of meaning. Importantly, during the process, the teachers learned to focus on students' thinking. Although the US teachers found the practice of neriage somewhat difficult to implement, they agreed that a classroom learning community that includes disagreement and conflict resolution over mathematical reasoning has the effect of providing a forum for students to put into practice the habits of mind, as well as the speech and actions, valued by the community of mathematical practitioners.

The second article in this issue is focused on quality instruction. In "Measuring the mathematical quality of instruction," the authors, publishing under the title of their project, describe a framework and an instrument for measuring the mathematical quality of mathematical instruction. Their goal was to quantify the mathematical quality of teachers' work. As the authors argue, it is important to highlight the features of the mathematics in teaching (such as key mathematical ideas, the quality of mathematical representations and explanations and high-quality tasks). Whilst they do not argue that researchers should cease investigating pedagogical approaches used by teachers, they do advocate separating the features of the mathematics as presented in teaching, away from pedagogical approaches. Whilst reform efforts tend to conflate the two aspects, in the authors' view, the separation offers researchers more clarity and more opportunities for studying the relation between teacher knowledge and instruction and ultimately more opportunities for studying student learning.

A series of video recordings of classroom instruction led to the development of an observational instrument. Nine recordings were taken from the classroom work of each of 10 teachers, over the course of 2 years. Teachers in the professional development workshops taught various grades from 2nd to 6th and completed a paper and pencil survey, designed to assess their mathematical knowledge for teaching. They also participated in post-lesson interviews. The framework and coding system that resulted comprised several major constructs: richness and development of the mathematics, responding to students, 
connecting practice to mathematics, language, equity and presence of mathematical errors. The challenge of inter-rater reliability meant that the rubric development and data coding took around 2 years to complete. The instrument for measuring the quality of mathematics instruction is considered by the authors to be under ongoing development.

John M. Francisco and Carolyn Maher report on a study of an after-school classroombased research project. In "Teachers attending to students' mathematical reasoning: Lessons from an after-school research program," the authors document the experiences of a group of elementary and middle school mathematics teachers involved in a 1-year project, aimed at supporting the mathematical experiences of 6th grade low SES students. Whilst the students engaged collaboratively in challenging well-defined mathematical investigations, the teachers in the research focused their attention on observing the students' mathematical activity. The teachers reported their observations in debriefing meetings with the researcher after each research session. Videotapes and the transcripts of the debriefing session constituted the main dataset.

The mathematical tasks that the students worked on provided them with opportunities for activity and discussion that focused explicitly on central mathematical ideas and processes. By paying attention to noticing and by listening carefully to what students have to say, the process enabled the research teachers to make significant inroads into understanding students' mathematical reasoning. They came to appreciate that students are able to draw on their own strategies, develop a language to describe and justify their thinking, distinguish between levels of justification and make their own discoveries. The teachers came to respect the researchers' decision for them to step out of the classroom interactions and to avoid resolving competing student claims. In doing that, the teachers witnessed how the students collectively resolved their mathematical disagreements. In short, they observed how the students participated in a microcosm of mathematical practice, developing mathematical ideas, language and methods.

Our final article in this issue is focused on prospective teachers. Sandy M. Spitzer, Christine M. Phelps, James E. R. Beyers, Delayne Y. Johnson and Elizabeth M. Sieminski report on an intervention aimed at "Developing prospective elementary teachers' abilities to identify evidence of students' mathematical achievement." First- and second-year prospective elementary teachers, across a number of classrooms, were presented with two 75-min lessons and given follow-up assignments, both targeting errors made regarding the interpretation of students' responses. Pre- and post-tests took place. Specifically, the prospective students read a researcher-designed transcript of a classroom lesson on place value, organised around three sections, none of which incorporated evidence of students achievement of the learning goal. The prospective students were provided with further information and given the opportunity to alter their ratings for the three sections. Following a whole-class discussion, students were invited to identify learning goals achieved. The second lesson employed a card-sorting activity to focus attention on procedural and conceptual responses.

Overall, prospective students improved their analysing skills. As a result of the intervention, they relied less on teacher statements than on student thinking. They also learned to disregard irrelevant evidence. However, after the intervention, most prospective students continued to accept a set of procedural steps as evidence of understanding of the underlying concepts. Small distractors, such as calculators, tended to influence how evidence was interpreted. However, the researchers were encouraged by the results of the intervention, developed with open-ended instructions and the free expression of ideas. In that, it developed skills in determining what counts as evidence, it prepared prospective students for life-long learning in the classroom. 
All four articles describe elements of practice that either enhances the education of mathematics teachers or the development of teaching that promotes students' successful learning of mathematics. We trust that the articles will deepen your understanding of mathematics teaching and mathematics teacher education in many ways. Our hope is that they will also provide a springboard for future work. 